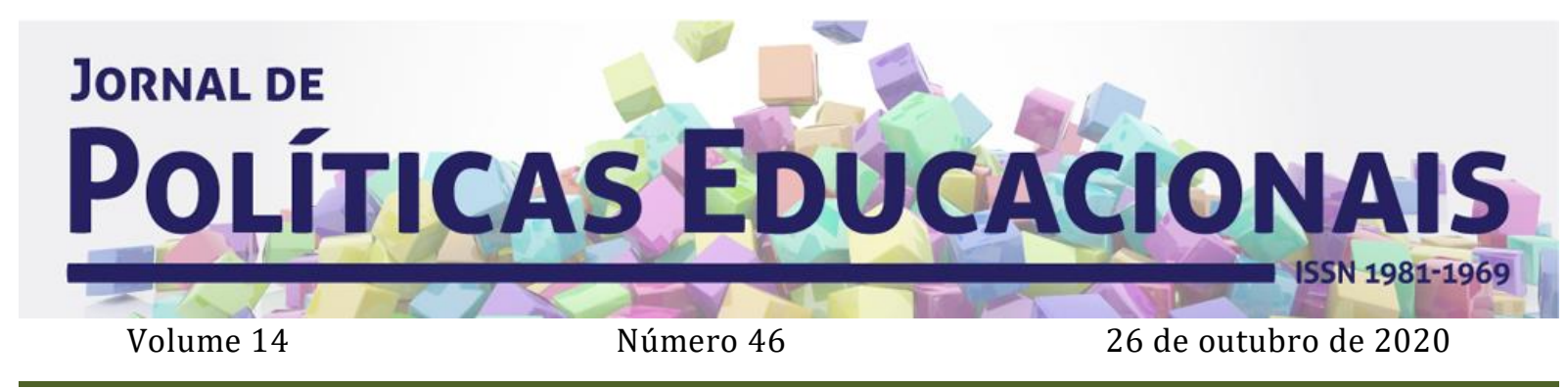

\title{
A (in)efetividade da Lei n.o 11.738/2008 à luz das decisões do Supremo Tribunal Federal
}

\section{The (in)effectiveness of the Law No. 11,738/2008 in the light of the Federal Supreme Court's decisions}

\section{La (in)efectividad de la Ley n.o 11.738/2008 a la luz de las decisiones del Supremo Tribunal Federal}

Ana Cláudia Dos Santos Rocha ${ }^{1}$

Citação: ROCHA, A. C. dos S. A (in)efetividade da Lei n.ำ 11.738/2008 à luz das decisões do Supremo Tribunal Federal. Jornal de Políticas Educacionais. V. 14, n. 46. Outubro de 2020.

http://10.5380/jpe.v14i0.74105

Resumo: 0 estudo objetiva avaliar a atuação do Supremo Tribunal Federal (STF) no que se refere à efetividade das políticas públicas de valorização dos docentes da educação básica posterior à Lei n.o 11.738/2008. Utiliza-se a pesquisa documental, com enfoque qualitativo e análise de conteúdo pautada na perspectiva teórica neoinstitucionalista, pela abordagem da ação pública. Investiga-se os processos e os resultados das demandas coletadas, os efeitos da judicialização e a interface de direitos fundamentais direito à educação, ao trabalho digno, e o acesso à justiça - afetos à valorização docente, considerando-a como aquela que atende ao tripé remuneração/carreira/formação. Ao final, constatou-se que a judicialização pode ser um instrumento a mais para garantir a efetividade de tais políticas, todavia, não tem atingido tal intuito por estar reduzida a questões econômico-financeiras.

Palavras-chave: Políticas de valorização docente; Judicialização; Efetividade; Supremo Tribunal Federal.

Abstract: The study aims to evaluate the Federal Supreme Court's (STF) performance with regard to the effectiveness of public policies to value teachers of basic education after the Law No. 11,738/2008. Documentary research is used, with a qualitative focus and content analysis based on the neoinstitutionalist theoretical perspective, by the approach of public action. The processes and the results of the collected demands are investigated, the effects of judicialization and the interface of fundamental rights - right to education, decent work, and access to justice - related to teacher's valuing, considering it as one that attends the remuneration/career/training tripod. Finally, it was found that judicialization could be an additional instrument to guarantee the effectiveness of such policies. However, it has not achieved this aim yet because it is reduced to economic and financial issues.

\footnotetext{
${ }^{1}$ Doutora em Educação pela Universidade Federal da Grande Dourados - UFGD. Professora Adjunta da Universidade Federal de Mato Grosso do Sul - UFMS/CPTL. Três Lagoas, MS. Brasil. Orcid: https://orcid.org/0000-0003-3591-1341 E-mail: advaclaudia@gmail.com
} 
Keywords: Teacher's valorization policies; Judicialization; Effectiveness; Federal Supreme Court.

Resumen: La investigación tiene como objetivo analizar el desempeño del Supremo Tribunal Federal (STF) con respecto a la efectividad de las políticas públicas para la valoración de los maestros de educación básica después de la promulgación de la Ley 11.738/2008. Se ha utilizado la investigación documental, con un enfoque cualitativo y con un análisis de contenido basado en la perspectiva teórica neoinstitucionalista, mediante el enfoque de la acción pública. Se han investigado los procesos y resultados de las demandas recogidas, los efectos de la judicialización y la interfaz de los derechos fundamentales - derecho a educación, al trabajo decente, y acceso a la justicia - que están relacionados con la valoración profesional de los docentes, considerándola como parte del trípode sueldo/carrera/capacitación. Al final, se descubrió que la judicialización puede ser un instrumento adicional para garantizar la efectividad de estas políticas, sin embargo, no han logrado este objetivo porque están reducidas a cuestiones económicas y financieras.

Palabras clave: Políticas de valoración docente; Judicialización; Eficacia; Supremo Tribunal Federal.

\section{Introdução}

A presente pesquisa é um recorte da tese de doutorado que tem como objeto de estudo as políticas públicas de valorização dos docentes da educação básica, cuja efetividade é analisada por meio das decisões do Supremo Tribunal Federal (STF), tendo como marco temporal a edição da Lei n. ${ }^{\circ}$ 11.738, de 16 de julho de 2008, que instituiu o Piso Salarial Profissional Nacional para os Profissionais do Magistério Público da Educação Básica (PSPN), atendendo ao Artigo 206, incisos V e VIII, da Constituição Federal (CF), de 5 de outubro de 1988.

Para tanto, a perspectiva teórica adotada foi o neoinstitucionalismo pela abordagem da ação pública, verificando: a atuação do STF para salvaguardar o cumprimento da Lei do PSPN, pautada na opção constitucional brasileira da tripartição dos poderes, conforme o Artigo $2^{\mathrm{o}}$ da CF, que coaduna com a teoria de freios e contrapesos (MONTESQUIEU, 1985), interpretada por meio dos controles recíprocos (CAPPELLETTI, 1993); a importância "das instituições/regras para a decisão, da formulação e implementação de políticas públicas" (SOUZA, 2006, p. 37); e os processos e os resultados, com base no pentágono das políticas públicas (LASCOUMES; GALÈS, 2012).

Cabe ressaltar que se trata de uma pesquisa qualitativa orientada à compreensão e à avaliação das tomadas de decisões pelo exame do conteúdo das sentenças do STF, possibilitando mapear a questão (ESTEBAN, 2010). Assim, encontrou-se no site oficial do órgão 20 decisões colegiadas e 241 monocráticas; após a leitura do teor delas, organizaram-se as análises: 1) das deliberações por colegiado, divididas por fixação do piso pela Lei do PSPN, responsabilidade subsidiária da União no cumprimento da Lei do 
PSPN e sua legitimidade passiva e repercussão geral; 2) das sentenças monocráticas, pautadas no mérito da ação.

Por sua vez, a análise documental, como técnica de abordagem de dados qualitativos, pautou-se na apuração de arquivos oficiais, como leis e decisões judiciais, identificando as informações atinentes ao objeto da pesquisa, primando pela investigação do (des)cumprimento da Lei do PSPN pelo poder público e da (in)aplicação pelo sistema judiciário, mediante avaliação da hermenêutica jurídica (LÜDKE; ANDRÉ, 1986).

Objetiva-se, de forma geral, averiguar a atuação do STF na efetividade dessas políticas a partir da Lei do PSPN; e, de maneira específica, levantar as demandas sobre a temática no STF e verificar seu posicionamento. Embora a valorização docente deva ser compreendida com base nas "condições de trabalho, remuneração e carreira, formação inicial e continuada" (MASSON, 2016, p. 157), não será abordada a formação inicial e continuada ante a ausência de lides acerca do tema.

\section{O papel da judicialização das políticas públicas: vantagens e desvantagens}

A judicialização é um instrumento hábil a garantir efetividade às políticas públicas ante o protagonismo da justiça decorrente dos mecanismos de ampliação do acesso à justiça previsto na CF (VERÍSSIMO, 2008). Todavia, existem críticas a tal instituto, entre elas, aponta-se a falta de legitimidade democrática do Judiciário, pois retiraria "dos poderes legitimados pelo voto popular a prerrogativa de decidir de que modo os recursos públicos devem ser gastos" (BARROSO, 2008, p. 24).

Nesse prisma, diferentes atores políticos podem fazer uso dos tribunais para retardar, impedir, desmerecer ou declarar sua oposição à determinada política pública, sendo usada como tática por membros adversários ou como instrumento de governo, quando o STF é acionado pelo administrador para que se pronuncie sobre uma política pública nos interesses do próprio governo, chamando-a de mão amiga (TAYLOR; ROS, 2008).

Outro aspecto que enseja reflexão é a falácia da neutralidade da figura do juiz que, de forma monocrática ou colegiada, decidirá a causa, pois, ao interpretar a lei para a aplicação no caso concreto, o que se vislumbra é uma luta simbólica entre as competências técnicas dos advogados "para fazerem triunfar sua causa; o efeito jurídico da regra, quer dizer, sua significação real, determina-se na relação de força específica entre os profissionais" (BOURDIEU, 2000, p. 225). 
Por seu turno, aqueles que defendem a judicialização rebatem a crítica da falta de legitimidade com fulcro em que "o procedimento legislativo pode dar origem à tirania da maioria e que essa maioria, constantemente, viola ou constrange o exercício de direitos individuais ou das minorias" (BARBOZA; KOZICKI, 2012, p. 64). Assim, uma das vantagens da judicialização é a proteção dos direitos fundamentais das minorias, "podendo-se afirmar que o controle de constitucionalidade é um dos maiores recursos disponíveis para as minorias políticas contra as decisões políticas majoritárias" (BARBOZA; KOZICK, 2012, p. 62).

Dentre os efeitos da judicialização perante o desenho constitucional vigente, que ampliou o poder do STF e modificou os arranjos institucionais entre a democracia e o constitucionalismo (VIEIRA, 1994), pode-se citar o aumento de poder no sistema político do Judiciário, em específico do STF, cujas discussões têm versado sobre temas de natureza política e moral e expandiu sua atividade legiferante, passando "do campo do exercício de autoridade para o exercício de poder [...] fazendo do Tribunal um coautor do constituinte originário na arquitetura da representação política brasileira" (VIEIRA, 2008, p. 451).

Dessa forma, normatizadas as políticas públicas e instituídos os planos e programas para sua implementação, em caso de descumprimento - total ou parcial - do Poder Executivo, por ações contrárias ao determinado nesses instrumentos ou por omissão quando o Poder Legislativo regulamenta em contrariedade aos dispositivos Constitucionais, poderá o Poder Judiciário ser instado a se manifestar (CANELA JUNIOR, 2011).

A judicialização implica "que questões políticas e sociais não estão mais sendo decididas somente pelas instâncias políticas tradicionais - Executivo e Legislativo - mas também pelo Poder Judiciário" (RIBAS; SOUZA FILHO, 2014, p. 41). 0 Judiciário assume um papel de controle acerca da efetividade da política pública, não se restringindo à análise do (des)cumprimento da lei, mas ao exame da concretização das políticas públicas estabelecidas para a implementação dos direitos sociais (DUARTE, 2016). Nesse sentido, o controle de constitucionalidade rompe com a tradicional divisão dos poderes, politizando a atuação dos juízes, sem a vinculação partidária destes, mas sim aos objetivos do Estado (CANELA JUNIOR, 2011).

Destarte, o Judiciário passa a ser incluído nas discussões políticas antes adstritas a Legislativo e Executivo, e, apesar dos juízes não terem sido escolhidos pelo povo, já que não são eleitos, sua inserção nessa seara não ofende o princípio da democracia e 
estabelece um controle judicial aos outros Poderes, garantindo a proteção de direitos e garantias individuais e o controle das políticas públicas. Embora esse controle não assegure o sucesso de tais políticas, resulta na ampliação dos envolvidos na formulação delas, correspondendo a uma concepção contemporânea sobre democracia (APPIO, 2004).

Assim, “o papel do Judiciário é justamente preservar o processo democrático e promover os valores constitucionais" (RIBAS; SOUZA FILHO, 2014, p. 47), pois, ainda que uma lei precise da aprovação da maioria dos representantes eleitos pelo povo, não significa um reflexo da democracia; esta pressupõe também o respeito aos direitos fundamentais, inclusive das minorias. Para proteger de qualquer lesão (ou ameaça) ao direito fundamental, o Judiciário poderá ser acionado, garantindo o cumprimento e a realização das finalidades políticas da CF (RIBAS; SOUZA FILHO, 2014).

Posto isso, o cerne da pesquisa são dois direitos fundamentais sociais: à educação e ao trabalho digno, respaldados no Artigo 206, incisos V e VIII, da CF, que elegeu como princípio basilar da educação a valorização docente, assegurada por planos de carreira, ingresso exclusivamente por concurso de provas e títulos e PSPN, devendo o Judiciário analisar os meios empregados para atingir tal escopo.

Decorrente de preceitos constitucionais, editaram-se leis nos âmbitos federal, estadual e municipal para obter tal valorização; elaboraram-se planos de carreira; fixouse um piso salarial; estabeleceram-se metas e ações no PNE; criaram-se fundos para garantir seu custeio, entre outros. Com a aprovação da política de valorização docente, surge a possibilidade do controle judicial com o intuito de garantir suas finalidades, podendo o Judiciário determinar ações a serem efetivadas pelo poder público ou inibi-las, se inconstitucionais.

No entanto, ao desempenhar esse papel, é falacioso supor que o Judiciário se mantém neutro, já que as instituições não o são, e, ao decidir, definirá quem, quando, como e por quem a política de valorização deverá ser aplicada. Ao avaliar os atores que cooperam ou afrontam a definição da interpretação das normas, vislumbra-se toda uma análise de relações de poder ${ }^{2}$, interesses e pressões, o que resulta em decisões judiciais com imposições extremamente fortes para essa política, por interferir em seu processo de desenvolvimento e de mudanças (LASCOUMES; GALÈS, 2012).

\footnotetext{
2 “[...] poder significa toda probabilidade de impor a vontade numa relação social, mesmo contra resistências, seja qual for o fundamento dessa probabilidade" (WEBER, 1994, p. 33).
} 
Nesse sentido, a judicialização permite ao Judiciário controlar a garantia dos direitos fundamentais, dando efetividade às normas que versam sobre o assunto, fazendo com que os ditames constitucionais superem a mera condição de "folha de papel" e tenham aplicação fática em cada demanda, conforme suas especificidades e representações (BUCCI, 2009).

O papel do Judiciário, portanto, na efetividade da política pública de valorização docente é fazer com que o Estado cumpra os preceitos constitucionais e infraconstitucionais acerca do tema, embora haja críticas ao instituto, as suas vantagens e a sua importância para assegurar o equilíbrio dos três poderes, tornando-o essencial à garantia dos direitos sociais que se almejam com a política de valorização do educador.

\section{Análise da judicialização das políticas de valorização docente no Supremo Tribunal Federal}

O levantamento das ações julgadas pelo STF pautou-se nos descritores: "valorização docente", "jornada de trabalho docente, "remuneração docente" e "piso salarial do magistério", resultando nos seguintes dados:

Quadro 1 - Quantitativo por tema dos julgados do STF

\begin{tabular}{|c|c|}
\hline Valorização docente & $\begin{array}{l}\text { 1. ADI } 4167 \\
\text { 2. MC/ADI } 4167\end{array}$ \\
\hline Jornada de trabalho docente & $\begin{array}{l}\text { 1. ADI } 4167 \\
\text { 2. MC/ADI } 4167 \\
\text { 3.RE 158.396-7/SP }\end{array}$ \\
\hline Remuneração docente & $\begin{array}{l}\text { 1. ARE 1011942 AgR/SP } \\
\text { 2. MS 31642/DF } \\
\text { 3. ARE 799192 AgR/RS } \\
\text { 4. ADI 938-9 BA } \\
\text { 5. ADI } 4167 \\
\text { 6. MC/ADI } 4167\end{array}$ \\
\hline Piso salarial do magistério & $\begin{array}{l}\text { 1. Rp 1464/MG } \\
\text { 2. MC Rp 1464/MG } \\
\text { 3. ADI 120/AM } \\
\text { 4. RE 253.247-9 AgR/PR } \\
\text { 5. RE 292.659-1 AgR/PR } \\
\text { 6. ADI 4167 MC/DF } \\
\text { 7. ADI 4167/DF } \\
\text { 8. RE 843718 AgR/SC } \\
\text { 9. RE 844208 AgR/SC } \\
\text { 10. RE 859994 AgR/SC } \\
\text { 11. RE 894409 AgR/RS } \\
\text { 12. ARE 903173 ED/SC } \\
\text { 13. RE 912976 AgR/RS } \\
\text { 14. RE 934061 AgR/RS }\end{array}$ \\
\hline
\end{tabular}




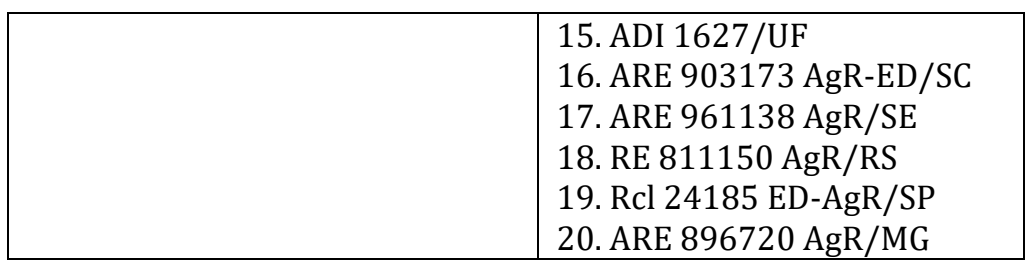

Fonte: elaborado pela autora com base no Banco Nacional de Dados do Judiciário (2018).

Em relação à valorização docente, encontraram-se duas ocorrências, ambas atinentes à constitucionalidade da Lei do PSPN. Acerca da jornada de trabalho, localizaram-se os itens 1 e 2 sobre a constitucionalidade da Lei do PSPN; e o 3, relativo ao recurso extraordinário, e que não será analisado por tratar de um assunto alheio ao objeto pesquisado.

Quanto à remuneração docente, o item 1 se refere à equiparação salarial; o 2 sobre aposentadoria; o 3, irredutibilidade de salários; o 4, regime de dedicação exclusiva dos professores da Universidade Estadual da Bahia; e o 5 e o 6, constitucionalidade da Lei do PSPN.

No tocante ao piso salarial do magistério, os itens 1 e 2 expõem a inconstitucionalidade do Artigo $1^{\text {o }}$ da Emenda Constitucional (EC) noㅡ 26, de 28/06/1987, da Constituição Estadual de Minas Gerais; o 3, a inconstitucionalidade dos Artigos 39, §1ํㅜㅇ 113, § 16; e 199, inciso II, alínea e da Constituição do Estado do Amazonas quanto ao piso salarial dos profissionais do magistério; o 4, o piso salarial dos trabalhadores do ensino; o 5, a fixação de piso salarial dos professores em múltiplos do salário mínimo; o 6 e o 7, a inconstitucionalidade da Lei do PSPN; o 8 e o 10, a modulação dos efeitos da decisão a respeito da constitucionalidade da Lei do PSPN; o 9, a exigibilidade do piso nacional da educação básica; o 11, a responsabilidade subsidiária da União no cumprimento da Lei do PSPN; o 12 e o 16, a implementação do piso nacional da educação básica; o 13 e o18, a legitimidade da União para figurar no polo passivo de demanda do piso salarial e apreciar o feito; o 14, a matéria fática e legal; o 15, o prazo para estados, Distrito Federal e municípios organizarem os respectivos planos de carreira e remuneração do magistério; o 17, a aplicabilidade da Lei do PSPN e o reajuste do piso salarial nacional do magistério; o 19, as Súmulas Vinculantes n.o 37 e 43; e o 20, a fundamentação sobre a Repercussão Geral - RE 936790 RG/SC e o Artigo 2oㅗ $§ 4^{\circ}$ o da Lei do PSPN.

Ainda nesse contexto, encontrou-se 305 decisões monocráticas, das quais 241 foram interpostas após a deliberação da Ação Direta de Inconstitucionalidade (ADI) n.o 4167. Constatou-se nas sentenças colegiadas que, em sua maioria, as ações versavam 
exclusivamente sobre remuneração. A jornada e a valorização docente só foram abordadas na ADI n. 4167; e o plano de carreira, apenas na ADI n. -1627 e respectiva Medida Cautelar (MC). Não houve demanda quanto à formação.

Afere-se, portanto, que a judicialização tem-se restringido à análise do aspecto econômico, atrelado à remuneração, embora não seja o único elemento a permear a valorização do magistério, que pressupõe a formação intelectual, a constituição de uma identidade profissional e o pagamento de salários dignos aos professores (MONLEVADE, 2000, p. 282).

Insurge, dessa forma, que além da análise do que tem ou não sido feito pelos gestores públicos para a implementação e o cumprimento das políticas públicas de valorização docente já positivadas, deve-se examinar as tentativas de burlar tais normatizações, como é o caso da ADI n. 4167 no STF, impetrada por cinco estados para invalidar a Lei do PSPN, sob a alegação de que deveria ser declarada inconstitucional, no que se refere a: jornada de 40 horas semanais, possibilitando a dedicação exclusiva e expediente integral; constituição da jornada em $2 / 3$ com alunos e $1 / 3$ para atividades de planejamento e preparação pedagógica, o que favorece a formação continuada e em serviço; obrigatoriedade do cumprimento do valor fixado no PSPN, que nivela os professores de todo o país em termos salariais, coibindo práticas de subemprego e necessidade de dupla jornada; prazos de implementação e vigência da Lei. Embora o STF tenha declarado a constitucionalidade da Lei do PSPN e determinado seu cumprimento obrigatório, gestores públicos ainda a desrespeitam, gerando inúmeras ações judiciais para sua efetivação.

Em relação à remuneração e à valorização do magistério, há decisões em plenário anteriores e posteriores à CF e posteriores à Lei do PSPN:

\begin{tabular}{|c|l|}
\multicolumn{2}{|c|}{ Quadro 2 - Decisões do STF } \\
\hline \multirow{2}{*}{ Decisões anteriores à CF/88 } & 1. Rp 1464/MG \\
& 2. MC/Rp 1464/MG \\
\hline & 1. ADI 938-9/BA \\
Decisões posteriores à CF/88 & 2. RE 253247 AgR/PR \\
& 3. RE 292659 AgR/PR \\
& 4. RE 158.396-7/SP \\
\hline & 1. ADI 4167 \\
& 2. MC/ADI 4167 \\
Decisões posteriores à Lei do & 3. ARE 1011942 AgR/SP \\
PSPN & 4. MS 31642/DF \\
& 5. ARE 799192 AgR/RS \\
& 6. RE 843718 AgR/SC \\
& 7. RE 844208 AgR/SC \\
\hline
\end{tabular}




\begin{tabular}{|c|c|c|}
\hline & & \begin{tabular}{|l|} 
8. RE 859994 AgR/SC \\
9. RE 894409 AgR/RS \\
10. ARE 903173 ED/SC \\
11. RE 912976 AgR/RS \\
12. RE 934061 AgR/RS \\
13. ADI 1627/UF \\
14. ARE 903173 AgR-D/SC \\
15. ARE $961138 \mathrm{AgR} / \mathrm{SE}$ \\
16. RE $811150 \mathrm{AgR} / \mathrm{RS}$ \\
17. Rcl 24185 ED-AgR/SP \\
18. ARE $896720 \mathrm{AgR} / \mathrm{MG}$
\end{tabular} \\
\hline
\end{tabular}

Fonte: elaborado pela autora com base no Banco Nacional de Dados do Judiciário (2018).

Do levantamento das decisões por colegiado do STF, constata-se que antes da CF e de sua EC n. ${ }^{\circ}$ 53, de 19/12/2006, e da Lei do PSPN, a fixação de um piso para os profissionais do magistério público já gerava discussões judiciais, cujas ações eram sobre: 1) criação e implementação de planos de carreira; 2) piso salarial para professores nas constituições estaduais; 3) piso salarial para professores com base no salário mínimo ou equiparação; 4) piso salarial nacional pela Lei do PSPN; 5) responsabilidade subsidiária da União no cumprimento da Lei do PSPN e sua legitimidade passiva; e 6) repercussão geral.

Ante o marco temporal eleito nesta pesquisa, serão analisadas as demandas atinentes aos itens 4, 5 e 6. Relativo ao piso pela Lei do PSPN, há uma ADI e sua respectiva MC, e na via recursal, há Recursos Extraordinários (RE), Agravos Regimentais (AgR), Recursos Extraordinários com Agravo (ARE) e Embargos de Declaração (DE), sobre a modulação dos efeitos da decisão sobre a (in)constitucionalidade da Lei do PSPN, a exigibilidade do piso e sua implementação e a legitimidade passiva da União nos feitos acerca da temática.

Nesse sentido, serão verificadas as decisões quanto à inconstitucionalidade da Lei do PSPN, sua exigibilidade e implementação, e à modulação dos efeitos da ADI, pautado no critério cronológico, da mais antiga a mais atual.

Os governadores dos estados de Mato Grosso do Sul, Paraná, Santa Catarina, Rio Grande do Sul e Ceará ajuizaram uma ADI relativa à Lei do PSPN. Por sua vez, atuaram no feito como amicus curiae: a Confederação Nacional dos Trabalhadores em Estabelecimentos de Ensino (CONTEE), o Sindicato dos Servidores do Magistério Municipal de Curitiba (SISMMAC), a Confederação Nacional dos Trabalhadores em Educação (CNTE), o Sindicato dos Trabalhadores em Educação Pública do Espírito Santo (SINDIUPES), o Sindicato dos Trabalhadores em Educação de Goiás (SINTEGO) e o 
Sindicato dos Servidores Públicos do Município de Fortaleza (SINDIFORT).

Além disso, eles interpuseram MC na ADI n. 4167, com o escopo de antecipação provisória da tutela jurisdicional, na qual se pleiteou a suspensão temporária dos efeitos da Lei do PSPN em seu Artigo $2^{\circ}$, caput e o $§ 1^{\circ}$ e e $4^{\circ}$; ;rtigo $3^{\circ}$, caput, incisos II e III; e artigo 8․ No que tange à MC/ADI n. 4167, convém analisar em tópicos a decisão do STF:

I. quanto ao alcance da expressão "piso", a cautelar foi deferida por maioria, manifestando-se o STF que, até decisão final da ADI, o piso deve ser entendido como remuneração e não como vencimento básico inicial da carreira;

II. acerca da fixação da carga horária máxima de 40h, limitando $2 / 3$ desta a atividades com educandos, a cautelar foi deferida por maioria, suspendendo a aplicação

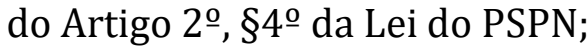

III. no que se refere ao Artigo $3^{\circ}$, inciso I, que previa a aplicação escalonada do piso a partir de janeiro de 2008, o STF interpretou que o início deveria se dar em janeiro de 2009.

Desse feito, extrai-se que permearam as discussões a violação da reserva da lei de iniciativa do Chefe do Executivo para dispor sobre o regime jurídico do servidor público (Artigo 61, $\S 1^{\circ}$, inciso II, alínea c da CF), a contrariedade ao pacto federativo (Artigo 60 , $\S$ $4^{\circ}$, inciso I da CF) e o princípio da proporcionalidade. Sobre este último, segundo os autores da ADI e da respectiva MC, a Lei do PSPN implicaria um aumento desproporcional e imprevisível dos gastos com a folha de pagamento, tendo em vista que a redução da jornada com alunos ensejaria a necessidade de contratação de outros profissionais.

Ademais, da ementa e do teor da decisão, observa-se que a medida foi parcialmente deferida e a votação não foi unânime em todos os pontos, motivo pelo qual se demonstra salutar a análise dos tópicos do pleito e o fundamento da deliberação. Um dos temas suscitados é o Artigo $2^{\circ}$, caput, e o $§ 1^{\text {o }}$ da Lei do PSPN, acerca do alcance da expressão "piso", ou seja, vencimento básico inicial ou global, e da fixação da jornada de trabalho.

Outro aspecto a ser examinado são as alegações de: 1) ser desproporcional a redação do artigo em epígrafe, ofensiva à legislação orçamentária, com ausência de relação entre fixar o piso e estabelecer a jornada, bem como infringir a competência do Chefe do Executivo estadual ou municipal para regular o regime jurídico de seus servidores (Artigo 61, $\S^{o}$ 1ํo , inciso II, alínea c da CF); 2) violação ao pacto federativo (Artigo $1^{\circ}$, caput, e $\S 1^{\circ}$, e Artigo 60, $\S 4^{\circ}$, inciso I da CF); e 3) ofensa ao princípio da proporcionalidade, tanto no aspecto pedagógico quanto financeiro. Questionou-se, ainda, 
o Artigo 3ㅜㅗㄱ incisos II e III da Lei do PSPN, sob a alegação de descumprimento ao Artigo $169, \S 1^{\circ}$ da CF.

Assim sendo, da observação dos votos dos ministros, percebe-se que vários deles salientaram a importância da lei da valorização do magistério e da redução de desigualdades regionais dos profissionais da educação básica. Ademais, decidiram que o Artigo $2^{\circ}$ da Lei n. $\stackrel{0}{11.738 / 2008}$, até julgamento final, deveria ser aplicado no sentido de piso como remuneração, ou seja, o valor global dos vencimentos. Também deferiram a cautelar em relação ao Artigo $2^{\circ}$, $§ 4^{\circ}$, e interpretaram o Artigo 3oㅡㄹ estabelecendo o prazo para cálculos a partir de $1^{\text {o }}$ de janeiro de 2009.

Ressalte-se que tal interpretação dada à lei somente teve validade até o final da decisão da ação principal, a ADI n. 4167, cujo inteiro teor da decisão foi publicado em 24 de novembro de 2011, isto é, dois anos após a publicação da deliberação da cautelar e três anos após a publicação da lei

Sobre a ação principal, a ADI n.o 4167, que suscitava a análise da inconstitucionalidade da Lei do PSPN e a interpretação de alguns de seus dispositivos, o STF declarou sua constitucionalidade e, divergindo da medida cautelar, a expressão "piso" foi considerada o vencimento inicial, e não a remuneração global. Em síntese, foi

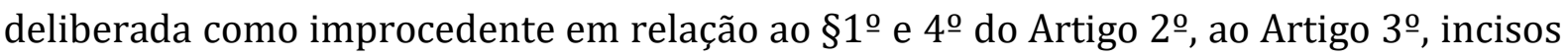
II e III, e ao Artigo 8ํ․ Conforme extrato da ata, merece destaque a divergência de votos a respeito do § 4ำ, do Artigo $2^{\circ}$, que resultou na não aplicação da eficácia erga omnes e do efeito vinculante da decisão relativo a tal dispositivo, culminando na Repercussão Geral

Após o STF ter afirmado ser constitucional a Lei do PSPN, inúmeras ações foram ajuizadas em primeira instância para exigir o cumprimento do piso e da jornada docente, nos moldes preceituados pela lei em comento.

Salienta-se que, em virtude da possibilidade dos professores da rede pública serem regidos pela Consolidação das Leis do Trabalho (CLT) ou por estatuto próprio, tais ações foram ajuizadas tanto na Justiça Comum (em se tratando de estatutários), como na Justiça do Trabalho (quando celetistas), por meio de ações propostas individual ou coletivamente. Por envolver matéria de ordem constitucional, algumas delas chegam pela via recursal ao STF e, até o momento, localizam-se 12 decisões por plenária, 241 deliberações monocráticas e uma repercussão geral sobre a aplicação da Lei do PSPN após a sentença da ADI n. $\stackrel{0}{4} 167$.

Destarte, em seção plenária foram decididos: RE 843718 AgR/SC; RE 844208 
AgR/SC; RE 859994 AgR/SC; RE 894409 AgR/RS; ARE 903173 ED/SC; RE 912976 AgR/RS; RE 934061 AgR/RS; ARE 903173 AgR-ED/SC; ARE 961138 AgR/SE; RE 811150 AgR/RS; Rcl 24185 ED-AgR/SP e ARE 896720 AgR/MG.

Assim, os RE 843718 AgR/SC, RE 844208 AgR/SC e RE 859994 AgR/SC versaram sobre os efeitos da modulação da decisão proferida na ADI n. 4167 e foram improvidos não pelo mérito, mas pela inadequação da peça recursal para discutir o pleiteado com o escopo de modificar a decisão do tribunal de origem. Segundo os ministros, o recurso interposto não se destina à revisão do conjunto probatório.

Cabe mencionar que os aspectos processuais não são pertinentes a esta pesquisa, mas sim o mérito das decisões analisadas. Nesse sentido, destaca-se que os recursos improvidos decorrem de ação individual de professoras da rede municipal de Apiúna/SC e de interpretação de legislação municipal própria, sua adequação à Lei do PSPN e a modulação dos efeitos da decisão da ADI n.o 4167, tendo as requerentes solicitado em primeira instância que sua remuneração fosse adequada ao piso salarial nacional, alegando que o Plano de Carreiras do município o vencimento dos professores no valor de $\mathrm{R} \$ 750,00$, portanto, abaixo do piso. Todavia, o tribunal de origem compreendeu que o valor de R\$750,00 não se refere aos vencimentos, "mas sim o salário inicial, sobre o qual incidiriam percentuais de acréscimo na seguinte ordem: 50\% para o servidor que possuir licenciatura plena, 10\% para o servidor que possuir especialização, 10\% para mestrado, e $24 \%$ para doutorado" (BRASIL, 2014, p. 5).

Além disso, apreendeu o juízo a quo que os efeitos da ADI e, consequentemente, a vigência da lei e a aplicação do piso se iniciou em 27 de abril de 2011; e a requerente solicitou tal adequação desde 2010. Logo, o entendimento ante o fato de a requerente possuir licenciatura e especialização ensejava uma remuneração acima do piso salarial nacional, pois recebia a importância de $R \$ 1.533,89$, enquanto que o piso equivalia a $R \$$ 950,00 .

Relativamente ao mérito, a interpretação dada pelo juízo a quo merece reflexão, já que na decisão do STF da ADI n. 4.167 a expressão piso foi declarada como o vencimento inicial, e, no caso em tela, o valor de $\mathrm{R}$ \$1.533,89 só é atingido após incidência da titulação. Entretanto, no presente feito, o STF não analisou o mérito diante da inadequação da peça recursal.

Nesse contexto, percebe-se a inadequação da aplicação da lei do PSPN na rede em comento, muito embora a decisão judicial de primeira instância tenha se manifestado 
favorável ao entendimento de que a titulação pode ser considerada para a somatória do piso. Nota-se que essa não é a interpretação dada pelo STF em sede da ADI n.o 4167, a qual expressa que o piso é o vencimento inicial, e não a remuneração global, incluindo titulação e outras vantagens previstas no plano de carreira.

Da leitura do voto do ministro relator, extrai-se que a lei não traz a definição de piso, e se a expressão deve ser vista como remuneração global (consideradas as gratificações e as vantagens) ou como vencimento básico (sem as gratificações e as vantagens). Salienta-se que para algumas legislações nacionais, a expressão piso é utilizada para indicar o limite mínimo, ou seja, a remuneração. Contudo, essa não deve ser a interpretação no caso da Lei PSPN, pois seu intuito não se restringe a uma proteção mínima (remuneração), mas a uma política de incentivo (vencimento).

A compreensão do STF sobre a expressão piso é no sentido de que é "mais um mecanismo de fomento a educação do que simples norma de proteção mínima do trabalhador" (BRASIL, 2011, p. 49). Destarte, em seu voto, o Ministro Ricardo Lewandowski afirmou que "equiparar o piso à remuneração, que corresponde ao vencimento, acrescido de vantagens pecuniárias, esvaziaria não apenas o espírito da lei, mas também tornaria inócuos os eventuais estímulos salariais conferidos pelos entes federado" (BRASIL, 2011, p. 71).

Ademais, o Artigo $2^{\circ}$ da Lei do PSPN especifica em sua redação que o piso se refere ao profissional de "formação em nível médio". Portanto, parece equivocada a interpretação de um vencimento inicial para nível superior e outro para especialista, por exemplo; trata-se de formação, e não de início da carreira. Nesse diapasão, englobar a titulação no vencimento inicial com o escopo de atender o PSPN é uma manobra que ofende a decisão do STF na ADI n. o 4167. Desta feita, acredita-se que só não foi acolhido o pedido de revisão da sentença devido ao equívoco procedimental, a peça recursal inadequada.

Nesse prisma, o ARE 903173 ED/SC foi indeferido por não haver ofensa ao Artigo 93, inciso IX da CF, e óbice à discussão nos moldes peticionados com fulcro na Súmula do STF n. 279 , pois ensejaria reelaboração do quadro fático. Isso se pauta no entendimento de que a decisão a quo foi devidamente fundamentada. 0 teor da sentença recorrida foi no sentido de não haver descumprimento da rede estadual de Santa Catarina quanto ao piso salarial, tendo em vista que a autora era contratada por 20h/a (horas/aula), logo, o cálculo do pagamento deveria ser proporcional à carga horária, inferior às $40 \mathrm{~h} / \mathrm{a}$. Por sua 
vez, sobre a reserva de, no mínimo, 1/3 da jornada para atividades extraclasse, devido ao posicionamento do STF não ter efeito vinculante a esse enunciado, cabe a cada juízo deliberar a respeito, conforme o caso concreto, o que gerou o reconhecimento da Repercussão Geral. Assim, o ARE 903173 AgR-ED/SC foi declarado improcedente por aspectos processuais formais, por não ser a peça recursal adequada, dispensando comentários à ementa.

Por seu turno, o ARE 961138 AgR/SE foi julgado improcedente, pois a decisão recorrida estabelecia não haver ofensa à Lei de Responsabilidade Fiscal (LRF) na concessão do reajuste do PSPN a todos os servidores dessa categoria, sob a alegação de que Boquim/SE já havia extrapolado o limite prudencial de gastos com pessoal no ano de 2012. O município tenta descumprir a Lei do PSPN sob pretexto de desrespeito à LRF, suscitando um conflito entre a Lei do PSPN e a LRF. No entanto, tal conflito não foi reconhecido, já que a LRF enseja a fiscalização dos gastos pelo Tribunal de Contas, mas não é óbice para o cumprimento da Lei do PSPN, pois os professores não são os únicos servidores e o teto prudencial para as despesas com a folha de pagamento pela administração pública deve ser examinado em seu montante geral, considerando todos os agentes públicos, e não uma categoria.

Nessa perspectiva, configurados os gastos acima do teto prudencial, as medidas a serem aplicadas referem-se primeiro à dispensa de assessores, de contratos temporários sem concurso ou de processo seletivo, de cargos comissionados ou de função de confiança. Logo, o desacato à Lei do PSPN sob a alegação de extrapolar as despesas deveria demonstrar que todas essas ações foram adotadas e que a receita era insuficiente, o que possibilitaria a complementação da União, conforme preceituado na Lei do PSPN, ou seja, de qualquer forma não infringiria a LRF.

Já o Agravo Regimental nos Embargos Declaratórios referentes à Reclamação Trabalhista n. ${ }^{\circ}$ 24.185, originária do Tribunal Regional do Trabalho da 15aㅗ Região, foi indeferido com aplicação de multa ao agravante na importância de 5\% sobre o valor da causa.

Embora a avaliação das decisões recorridas não seja objeto desta pesquisa, no caso em análise, convém informar o teor da deliberação do TRT 15a Região - tribunal a quo que condenou o município de São Joaquim da Barra/SP ao pagamento das diferenças salariais advindas da Lei do PSPN e do plano de carreira, não configura ofensa às Súmulas Vinculantes n. ${ }^{\circ} 37$ e 43, pois a adequação salarial não se pautou em aumento do salário- 
base com fulcro no princípio da isonomia, nem houve transposição de cargo público.

Na referida situação, a reclamante foi aprovada em concurso público e empossada no cargo de babá em 2003. Entretanto, em 2008, a nomenclatura "babá" foi alterada para educadora por legislação local e o edital do concurso apresentava como requisito a formação em magistério em nível médio ou em Pedagogia, o que motivou o juízo a quo a entender que se enquadrava na Lei do PSPN e no plano de carreira.

Por seu turno, o ARE 896720 AgR/MG foi indeferido, concluindo que o acórdão recorrido estava consoante o consolidado pela Corte na ADI n.. 4167, sendo deficiente a demonstração de repercussão geral da matéria constitucional.

Já os RE 894409 AgR/RS, RE 912976 AgR/RS, RE 934061 AgR/RS e RE 811150 AgR/RS versaram sobre a legitimidade passiva e a responsabilidade solidária ou subsidiária da União no cumprimento do pagamento do PSPN.

Posto isso, o STF entendeu que a Lei do PSPN é um exemplo de lei federal federativa transitiva, sendo a obrigação de implementação e de cumprimento do piso de responsabilidade de cada ente federativo, motivo pelo qual não é preciso mencionar a legitimidade passiva nem a responsabilidade civil solidária ou subsidiária da União, pois mesmo que fosse demonstrada sua omissão quando o Estado comprovasse a sua insuficiência orçamentária para a implementação do piso, caberia a ele acionar a União.

Outrossim, tendo em vista que na ADI n.. 4167 houve empate no que tange à inconstitucionalidade do $\S 2^{\circ}$, do Artigo $4^{\circ}$ da Lei n. ${ }^{\circ}$ 11.738/2008, que fixava $1 / 3$ da jornada para as atividades extraclasse sem aluno, tal parágrafo foi declarado constitucional, todavia, sem efeitos erga omnes, o que tem gerado uma série de ações a respeito da forma como as redes públicas estaduais e municipais aplicam tal dispositivo.

Assim, o STF reconheceu a repercussão geral ante os efeitos abrangentes do desfecho do assunto sobre a carreira do magistério em todos os entes federados, que em virtude de repetição do tema em inúmeras ações, incumbe ao STF definir a validade do $\S$ 4ํㅡ, do Artigo $2^{\circ}$ da Lei do PSPN, posto que na ADI n.ํ 4167 a decisão nesse tópico não vinculou os demais tribunais, motivo pelo qual se aguarda o posicionamento do STF para uniformizar as deliberações sobre a temática.

Em suma, das decisões monocráticas analisadas, a maior parte dos feitos versava sobre a obrigatoriedade do pagamento de remuneração aos professores nos moldes da Lei do PSPN, totalizando 219 ações em que o mérito discorria acerca da aplicação do PSPN. As demais eram: 14 sobre a reserva de $1 / 3$ da jornada para as atividades 
extraclasse sem alunos; duas a respeito do cumprimento do piso salarial nacional aos auxiliares de sala; uma acerca da utilização do PSPN para babá de centro de educação infantil; duas relativas à aplicação do PSPN aos docentes aposentados; duas sobre o direito à greve como instrumento para exigir o cumprimento do PSPN; e uma que questionava uma lei estadual que fixou o piso salarial inferior ao da Lei do PSPN. Essas informações se encontram sintetizadas no gráfico 1.

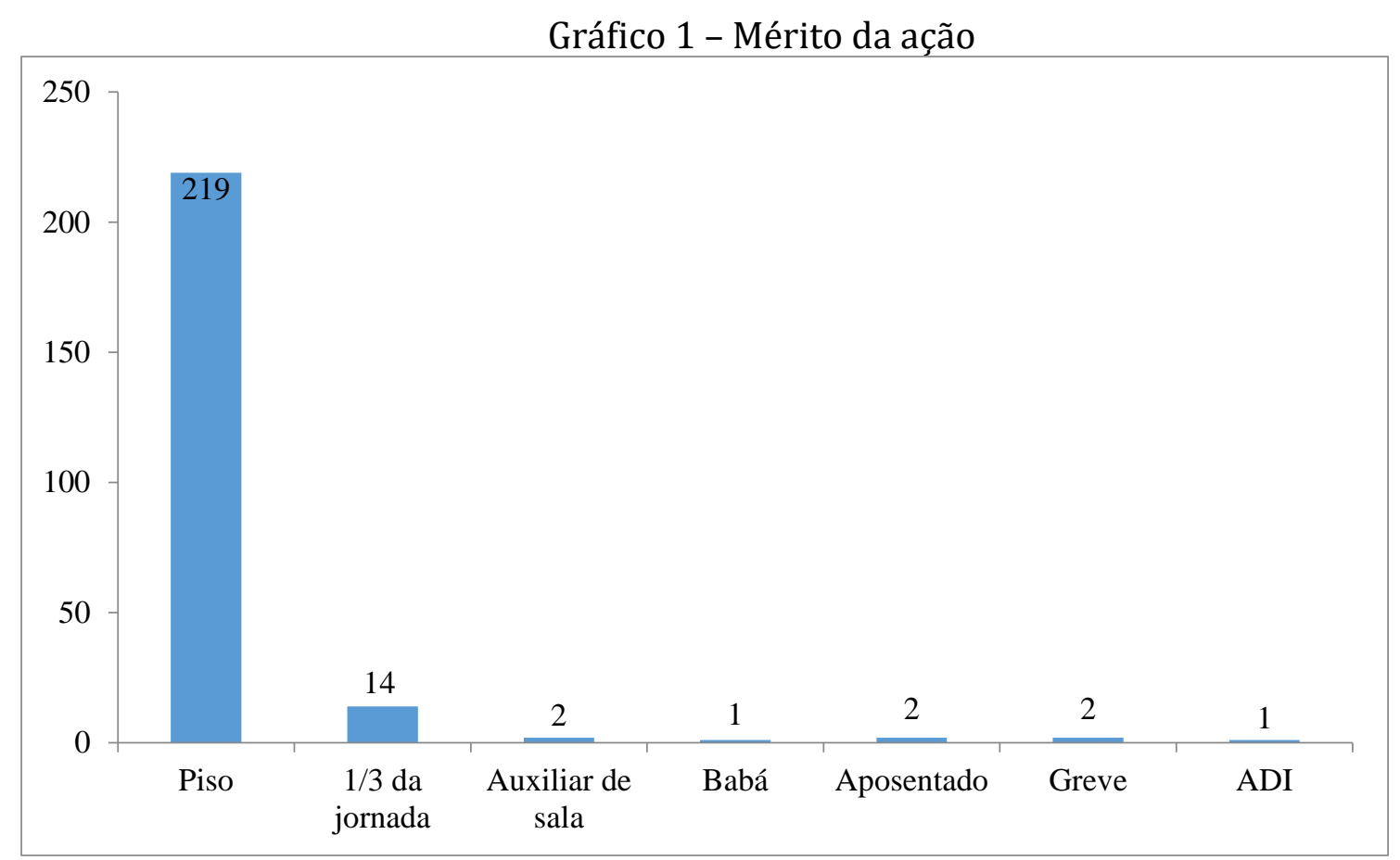

Fonte: elaborado pela autora com base no Banco Nacional de Dados do Judiciário (2018).

\section{Considerações finais}

O estudo das decisões proferidas pelo STF acerca das políticas públicas de valorização dos docentes da educação básica possibilitou a reflexão sobre o papel do controle judicial para a sua efetividade. Além disso, todas as demandas tiveram como cerne da discussão aspectos meramente econômicos e financeiros, sem a preocupação real com a qualidade do ensino, o trabalho digno e a valorização do professor.

Ademais, da análise dos processos, evidencia-se que nas ações individuais é significativa a quantidade de recursos que sequer são examinados em seu mérito, pelo erro formal (procedimental), impossibilitando a investigação do mérito (direito material), corroborando com o que Bourdieu (2000) denominou de luta simbólica entre os profissionais que atuam no processo, pois o desvio formal demonstra inequivocamente 
como a competência técnica impacta na aplicação da lei.

Por derradeiro, com base no pentágono das políticas públicas (LASCOUMES; GALÈS, 2012), os resultados dessa política, após a sua judicialização, demonstram que, embora o controle judicial seja um instrumento hábil para a sua efetividade, tem-se restringido a remuneração, o que limita a valorização docente a esta, não sendo suficiente para garanti-la.

Posto isso, o STF, na ADI n.o 4167, encerrou a celeuma do conceito de piso, limitando-o ao vencimento inicial e vedando a incorporação de gratificações ou qualquer outra verba em seu computo. Todavia, no que tange à composição da jornada com destinação de 1/3 para as atividades extraclasse, mesmo que considerada constitucional, não gerou efeitos erga omnes e foi declarada sem efeitos vinculantes, resultando na Repercussão Geral, não decidida até a presente data, o que indubitavelmente enfraqueceu a aplicabilidade do dispositivo.

Ante todo o exposto, constata-se que o controle judicial das políticas públicas de valorização docente pode ser considerado um instrumento a mais para tentar garantir a sua efetividade. Contudo, hodiernamente, devido às representações e aos resultados obtidos, tem-se apenas assegurado o controle do pagamento do piso, o que reduz o alcance dessa política e enfraquece os demais eixos.

\section{Referências}

APPIO, E. F. 0 controle judicial das políticas públicas no Brasil. 2004. 473 f. Tese (Doutorado em Direito) - Universidade Federal de Santa Catarina, Florianópolis, 2004.

BARBOZA, E. M. Q.; KOZICKI, K. Judicialização da Política e Controle Judicial de Políticas Públicas. Revista Direito GV, São Paulo, v. 8, n. 1, p. 59-86, jan./jun. 2012.

BARROSO, L. R. Ano do STF: Judicialização, ativismo e legitimidade democrática. Consultório Jurídico, São Paulo, 22 dez. 2008. Disponível em: https://www.conjur.com.br/2008-dez-

$\underline{22 / j u d i c i a l i z a c a o ~ a t i v i s m o ~ l e g i t i m i d a d e ~ d e m o c r a t i c a ? p a g i n a=3 . ~ A c e s s o ~ e m: ~} 28$ maio $\underline{2017}$.

BOURDIEU, P. 0 poder simbólico. Rio de Janeiro, RJ: Bertrand Brasil, 2000.

BRASIL. [Constituição (1988)]. Constituição da República Federativa do Brasil de 1988. Brasília, DF: Presidência da República, [2020]. Disponível em: http://www.planalto.gov.br/ccivil_03/Constituicao/ Constituiçao.htm. Acesso: 13 jun. $\underline{2020}$. 
BRASIL. Lei n.o 11.738, de 16 de julho de 2008. Estabelece o piso salarial profissional nacional para os profissionais do magistério público da educação básica. Brasília, DF: Presidência da República, 2008. Disponível em: http://www.planalto.gov.br/ccivil 03/ ato2007-2010/2008/lei/l11738.htm._Acesso em: 13 jun. 2020.

BRASIL. Lei Complementar n.o 101, de 4 de maio de 2000. Estabelece normas de finanças públicas voltadas para a responsabilidade na gestão fiscal e dá outras providências. Brasília, DF: Presidência da República, 2000. Disponível em: http://www.planalto.gov.br/ccivil 03/leis/lcp/lcp101.htm. Acesso em: 18 jun. 2020.

BRASIL. Supremo Tribunal Federal. Banco nacional de dados do judiciário. Jurisprudência (1988-2018). Pesquisa de jurisprudência. Disponível em: http://www.stf.jus.br/portal/jurisprudencia/pesquisarJurisprudencia.asp. Acesso em: 12 jan. 2019.

BRASIL. Supremo Tribunal Federal. Ação Direta de Inconstitucionalidade 4167. Administrativo e Constitucional Magistério. Educação básica: piso salarial fixado na Lei n.o 11.738/2008. É constitucional a norma geral federal que fixou o piso salarial dos professores do ensino médio com base no vencimento, e não na remuneração global. Recorrente: CONTEE /SINDIUPES [...]. Recorrido: MS/PR/RS/CE [...]. Relator: Ministro Joaquim Barbosa, Brasília, DF, 27 de abril de 2011. Disponível em: https://stf.jusbrasil.com.br/jurisprudencia/20627435/acao-direta-deinconstitucionalidade-adi-4167-df-stf?ref=juris-tabs. Acesso em: 18 jun. 2020.

BRASIL. Supremo Tribunal Federal (2 Turma). Recurso Extraordinário 843718/SC. Lei n.o 11.738/2008. Ação Direta de Inconstitucionalidade n.o 4.167. Administrativo e Constitucional Magistério. Educação básica: piso salarial fixado na Lei n. ${ }^{0}$ 11.738/2008. É constitucional a norma geral federal que fixou o piso salarial dos professores do ensino médio com base no vencimento, e não na remuneração global. Recorrente: Cleonice Nunes Rezini. Recorrido: Município de Apiúna. Relatora: Ministra Carmen Lúcia, Brasília, DF, 26 de outubro de 2014.2 Disponível em: https://stf.jusbrasil.com.br/jurisprudencia/25300212/recurso-extraordinario-re843718-sc-stf. Acesso em: 18 jun. 2020.

BUCCI, M. P. D. Controle judicial de políticas públicas: possibilidades e limites. Fórum Administrativo - Direito Público, Belo Horizonte, ano 9, n. 103, set. 2009.

CANELA JUNIOR, O. Controle judicial de políticas públicas. São Paulo, SP: Saraiva, 2011.

CAPPELLETTI, M. Juízes legisladores? Porto Alegre, RS: Sérgio Antonio Fabris Editor, 1993.

DUARTE, R. C. O caso da efetivação das políticas públicas de saúde: breves apontamentos para a atuação do Ministério Público. Boletim Científico ESMPU, Brasília, v. 15, n. 47, p. 149-180, jan./jun. 2016.

ESTEBAN, M. P. S. Pesquisa qualitativa em educação - fundamentos e tradições. Porto 
Alegre, RS: AMGH, 2010.

LASCOUMES, P.; GALÈS, P. Sociologia da Ação Pública. Maceió, AL: EDUFAL, 2012.

LÜDKE, M.; ANDRÉ, M. E. D. A. Pesquisa em educação: abordagens qualitativas. São Paulo, SP: EPU, 1986.

MASSON, G. A valorização dos professores e a educação básica nos estados. Revista Retratos da Escola, Brasília, v. 10, n. 18, p. 157-176, jan./jun. 2016.

MONLEVADE, J. A. C. Valorização salarial dos professores: o papel do piso salarial profissional nacional como instrumento de valorização dos professores de Educação Básica Pública. 2000. 315 p. Tese (Doutorado em Educação) - Universidade Estadual de Campinas, Campinas, 2000.

MONTESQUIEU, C. L. S. Do Espírito das Leis. São Paulo, SP: Abril Cultural, 1985.

RIBAS, G. P. P.; SOUZA FILHO, C. F. M. A judicialização das políticas públicas e o Supremo Tribunal Federal. Revista Direito, Estado e Sociedade, Rio de Janeiro, n. 44, p. 36-50, jan./jun. 2014.

SOUZA, C. Políticas Públicas: Uma revisão de literatura. Sociologias, Porto Alegre, ano 8, n. 16, p. 20-45, jul./dez. 2006.

TAYLOR, M. M; ROS, L. Os Partidos Dentro e Fora do Poder: A judicialização como resultado contingente da estratégia política. DADOS - Revista de Ciências Sociais, Rio de Janeiro, v. 51, n. 4, p. 825-864, 2008.

VERÍSSIMO, M. P. A Constituição de 1988, vinte anos depois: Suprema Corte e Ativismo Judicial “à brasileira”. Revista Direito GV, São Paulo. v. 4, n. 2, p. 407-440, jul./dez. 2008.

VIEIRA, O. V. Império da Lei ou da Corte? Revista USP, São Paulo, n. 21, p. 70-77, maio 1994.

VIEIRA, O. V. Supremocracia. Revista Direito GV, São Paulo, v. 4, n. 2, p. 441-464, jul./dez. 2008.

WEBER, M. Economia e Sociedade. Brasília, DF: Ed. UnB, 1994. 

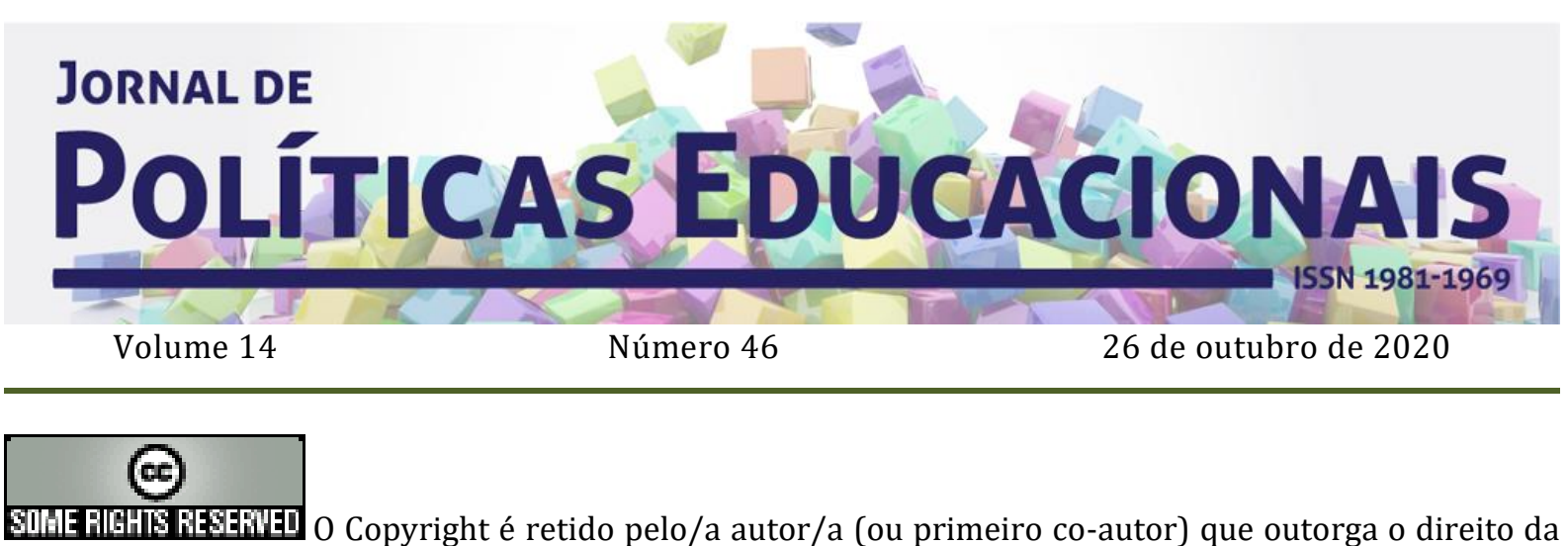

0 Copyright é retido pelo/a autor/a (ou primeiro co-autor) que outorga o direito da primeira publicação ao Jornal de Políticas Educacionais. Mais informação da licença de Creative Commons encontram-se em http://creativecommons.org/licenses/by-nc-nd/2.5. Qualquer outro uso deve ser aprovado em conjunto pelo/s autor/es e pelo periódico.

JoRnal De Políticas EduCACionais é uma publicação do Núcleo de Políticas Educacionais do Setor de Educação da Universidade Federal do Paraná - NuPE/UFPR, em consórcio com a Linha de Pesquisa em Políticas Educacionais do Programa de Pós-Graduação em Educação - PPGE/UFPR, que aceita colaboração, reservando-se o direito de publicar ou não o material espontaneamente enviado à redação. As colaborações devem ser enviadas ao NuPE/UFPR, conforme orientações contidas nas páginas do periódico na internet: http://revistas.ufpr.br/ipe.

\author{
Indexação: \\ BBE - Biblioteca Brasileira de Educação (MEC/INEP) \\ Clase (Base de Datos Bibliográfica de Revistas de Ciencias Sociales y Humanidades) \\ Diadorim - Diretório de Política de Acesso Aberto das Revistas Científicas Brasileiras (IBICT) \\ Google Scholar \\ Index Copernicus \\ Portal de Periódicos (CAPES) \\ SER - Sistema Eletrônico de Revistas da Universidade Federal do Paraná (SER/UFPR) \\ Sumários de Revistas Brasileiras (FUNPEC-RP) \\ DRJI - Directory of Research Journals Indexing
}

(Periódico integralmente disponível apenas em via eletrônica)

Jornal de Políticas Educacionais / Núcleo de Políticas Educacionais da Universidade Federal do Paraná -

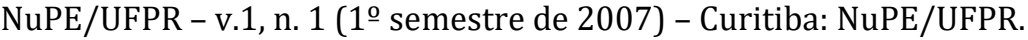

Volume 14, número 46 - Outubro de 2020

ISSN 1981-1969

1. Educação - Periódicos. 2. Política Educacional - Periódicos. I. NuPE/UFPR

Comitê Editorial:

Elisângela Scaff (UFPR)

Daniela de Oliveira Pires (UFPR)

Conselho Editorial:

Andréa Barbosa Gouveia (UFPR - Brasil), Cesar Tello (Universidad Nacional Tres Febrero, Argentina), Fernanda Saforcada (Universidad de Buenos Aires - UBA - Argentina), Gladys Beatriz Barreyro (USP Brasil), Gustavo Enrique Fischman, (Arizona State University - USA), Jefferson Mainardes (UEPG - Brasil), 
ROCHA, A. C. dos S. A (in)efetividade da Lei n. ${ }^{\circ} 11.738 / 2008$ à luz das decisões do Supremo Tribunal Federal

João Ferreira de Oliveira (UFG - Brasil), Juca Gil (UFRGS - Brasil), Luiz Souza Júnior (UFPB - Brasil), Ney Cristina Monteiro de Oliveira (UFPA - Brasil), Nicolás Bentancur, (Universidad de la República de Uruguay), Robert Verhine (UFBA - Brasil), Rosana Cruz (UFPI - Brasil), Rubens Barbosa Camargo (USP - Brasil), Sebastián Donoso Díaz (Universidad de Talca - Chile), TheresaAdrião (UNICAMP - Brasil), Vera Peroni (UFRGS - Brasil).

Créditos e Agradecimentos:

Revisão de Língua Portuguesa, Abstract e Resumen: PROGRAMA DE APOIO ÀS PUBLICAÇÕES CIENTÍFICAS PERIÓDICAS DA UFPR

Arte e diagramação: TIAGO TAVARES (thiagotav@gmail.com)

\author{
Jornal de Políticas Educacionais \\ Universidade Federal do Paraná \\ Setor de Educação \\ Núcleo de Políticas Educacionais - NuPE/UFPR \\ Avenida Sete de Setembro, 2645 \\ $2^{\circ}$ andar, Sala 213 \\ 80.230-010 - Curitiba - PR - Brasil \\ Tel.: 41-3535-6264 \\ jpe@ufpr.br \\ http://revistas.ufpr.br/jpe
}

